\title{
Queers in Quarantines: Impact of Lockdown and Social Distancing on Psychology of Transgender
}

\author{
Sugyanta Priyadarshini ${ }^{1}$ (D) Sukanta Chandra Swain ${ }^{1}$
}

Received: 15 August 2020/Accepted: 29 March 2021/Published online: 17 April 2021

(C) The Institution of Engineers (India) 2021

\begin{abstract}
The unexpected emergence of a novel and dangerous virus widely known as coronavirus (COVID-19) has brought in global health crisis and has socioeconomically disrupted the lives of people to a significant extent. In order to curb the spread of the contagious infection, nationwide lockdown and sometimes shutdown is announced by the state which has adversely affected the lives of many members of transgender community who are solely dependent on social interactions for their livelihood such as begging in streets and trains, entertaining in marriage functions and baby showers, engaging in prostitution. Consequently, the lost livelihood, clogged income stream, exhausted savings, burden of debt have imbued psychological distress among them. This study has analyzed the association of social distancing and lockdown constraints to psychological outcomes (i.e., depression, anxiety issues, financial stress, lack of social support, and loneliness) among transgender people amid COVID-19. Transgender participants $(N=150$, mean age $=42.5)$ were selected through snowball sampling from India who responded to the questionnaire through both online platform and offline modes. Findings show that there is positive association between any two of the variables and the degree of association is quite reasonable with the range from 0.534 to 0.945 . Further, in order to evaluate the hypothesis a series of regression analysis is conducted. Results highlight the negative impact of social distancing and lockdown constraints on psychology of transgender individuals.
\end{abstract}

Sugyanta Priyadarshini

sugyanta.priyadarshini@kiit.ac.in

1 School of Humanities, Kalinga Institute of Industrial Technology, Bhubaneswar, India
Keywords Transgender - Quarantine - Social Distance · Lockdown · Psychology · COVID-19

\section{Introduction}

On January 30, 2020, the World Health Organization (WHO) has declared SARS-COVID-19 (severe acute respiratory syndrome coronavirus) as a global health concern. COVID-19 has adversely impacted the health, economy and well-being of the humans of almost every country in the globe including India [1]. India at the end of July 2020, exhibited third highest number of documented cases throughout the world. In the early August 2020, the infection and fatality count for COVID-19 has reached to 1,695,988 positive tests and 36,511 demises in India. However, COVID-19 pandemic has stemmed an unprecedented human and health crisis. In this grim situation, there is an uncertainty about the length and severity of the pandemic. The financial system of India has faced a dramatic impact and the intensification of the corona crisis has degraded the situation from bad to worse. Consequently, the COVID-19 Pandemic has turned to be more than just a health crisis with critical social, economic and political consequences. The actions undertaken to curtail the spread of corona virus infection have triggered an economic turndown. The Coronavirus infection has disrupted the lives of many specifically the transgender community who stand at the front line in this crisis. The majority section of transgender community is solely dependent on social interaction based jobs like traditional begging in the crowded places like railway stations, streets and market places, selling sex at red light areas and entertaining in marriage functions and baby shower occasions. However, the state in order to slow down the spread of coronavirus 
infection [2], has imposed weekly lockdowns and complete shutdown of commercial establishments, transportation services and working spaces and has prohibited the social and religious gatherings, thereby making it difficult for this marginalized community to earn a living and access food and other essentials. The stay-at-homes order by government has socially and economically disrupted the lives of transgender community resulting in financial instability, food insecurity, exhausted savings, postponement of sex reassignment surgery, delay in hormonal treatment and adverse psychological outcomes like depression, stress, anxiety imbuing from loneliness and lack of social support [3-5]. Consequently, majority of transgender individuals are vulnerable to unprecedented complications with mental, physical, and social well-being, as well as difficulties in accessing health care facilities amid COVID-19. However, as a socially secluded community, disparities faced by transgender people at the hands of the state in implementing biased legislative policies such as providing relief funds excluding transgender beneficiaries would possibly increase the risk of illness and fatality during COVID-19 pandemic [6]. According to 2011 census, the transgender count in India is recorded as 4.88 lakhs out of which a majority of transgender individuals are engaged in gig jobs for their daily earning. However, amid COVID-19, nationwide lockdown has clogged their income stream pushing them deeper toward crisis. The National Institute of Social Defense has forwarded Rs 1500 to approximately 4500 transgender individuals from different states, which is admirable but practically this can be considered as a drop in the ocean [7]. Similarly, the steps taken by government of Uttar Pradesh in providing financial aid and ration is commendable but it again secluded the transgender community from its list of beneficiaries [8].

Before pandemic, transgender community is socially ostracized as they transgress the societal norm of bilateral division of sexes between male and female [9]. As a result, majority of transgender individuals face discrimination in accessing education, medical facilities and job opportunities; thereby enrolling themselves in menial jobs to earn their daily bread and butter [10]. Thus, the pandemic scenario has opened up a battlefront for the millions of transgender people to make their ends meet. This community is at heightened risk of hunger and poverty due to social distancing protocols and travel restrictions amid COVID-19 pandemic. Due to the sudden emergence and hasty diffusion of COVID-19 infection, research work in understanding the psychological impact on transgender people is limited. Further, the adverse impact of social distancing amid COVID-19 pandemic on socioeconomic activities and daily lives were associated with greater psychological difficulties. The outcomes of the previous research work on psychological distress due to social distancing in pandemic situation are discussed such as Hawryluck et al. [11] found that $31.2 \%$ people were suffering from depression and $28.9 \%$ people were suffering from anxiety issues due to the outbreak of 2003 SARS. Similarly, during the outbreak of 2009 HINI pandemic, people were at heightened risk of anxiety issues [12]. However, to explore more on impact of lockdown and social distancing on psychology of transgender people, the current study examined the association of social distancing and lockdown constraints on psychological outcomes (i.e., depression, anxiety issues, financial stress, lack of social support, and loneliness) of transgender people. The chapter has also measured the degree of psychological difficulties among transgender people amid pandemic. Further, the research work establishes a positive association between social distancing in COVID-19 with psychological difficulties.

\section{Method}

\section{Participants}

The participants in the study included 150 transgender respondents from India who responded to the questionnaire through both online platform and offline modes from April 20, 2020 to July 25, 2020. Snowball sampling was used to select the sample. All states were taken into consideration except 8 states (Arunachal Pradesh, Manipur, Meghalaya, Nagaland, Mizoram, Himachal Pradesh, Chhattisgarh, Tripura). The states with greatest representation in sample were Odisha (42\%), West Bengal (10\%), Maharashtra (5.33\%), Uttar Pradesh (5.33\%), Karnataka (5.33\%), Rajasthan (4\%), Punjab (3.33\%), Haryana (2.66\%), Madhya Pradesh (2.66\%), Kerala (2.66\%), Jharkhand $(2.66 \%)$, Uttarakhand (2.66\%), Gujarat (2.66\%), Bihar (2.66\%), Telangana (2\%), Assam (1.33\%), Tamil Nadu (0.66\%), Sikkim (0.66\%), Goa $(0.66 \%)$ and Andhra Pradesh $(0.66 \%)$. The age of respondents ranged between 20 and 70 years. Further, data were also collected regarding their educational attainment. $34.66 \%$ are illiterate, $26.66 \%$ have matriculated, $20 \%$ have completed their intermediate course, $14 \%$ are graduates and $4.66 \%$ have done their higher studies. The monthly income was categorized under three categories; $32 \%$ earned less than Rs 20,000 a month, $50 \%$ of the respondents earned within the range Rs 21,000-50,000 and $18 \%$ earned within the range Rs 51,000- 1,00,000. 32\% of respondents tested for COVID19 once and $1.33 \%$ are infected with coronavirus infection. 


\section{Procedure}

Statistical Package for social Sciences (SPSS) software is used to find the correlation between social distancing in COVID-19 with psychological difficulties. A consent form was filled up from every transgender respondent which informs that "Participants should provide accurate and true data to the best of their knowledge. If there is any strong reason to disbelieve the invalid data provided by the respondent, then the data will not be taken into consideration and the response will not be paid." The data collected through telephonic conversation were collected after attention check test. However, the attention items included two close ended questions (e.g., Do you want to respond to the questions asked in this conversation? and Are you satisfied with a remuneration of Rs 100 for your response to the questionnaire?) and one open ended question (e.g., What is the day today?). Those who cleared the attention check test where further allowed to respond to the questionnaire. The respondents who completely responded the entire questionnaire were rewarded Rs 100 each.

\section{Measures}

A questionnaire was forwarded to every respondents comprising of the details regarding their age, educational attainment, monthly income and nature of job (engaged in organized or unorganized sector). Respondents were requested to share their views regarding their experiences in the pandemic situation. A 25 item measure was developed to ask some related questions regarding the impact of lockdown and social distancing on psychology of transgender people. The two important questions from the present study were: (1) Social distancing status (i.e., Are you following the rules of the state government of staying back at home [0 = no, $1=$ yes], (2) Lockdown impact (i.e., To what extent the occurrence of this crisis has psychologically affected you?) Respondents replied to the latter question through 5 point Likert type scale ranging from 1 to 5 . $(1=$ no impact at all, $2=$ disturbed me slightly, 3 = irritated and frustrated to a certain extent, $4=$ went into depression, 5 = tried committing suicide).

A 21 item depression scale naming Depression Anxiety Stress Scales (DASS-21) [13] is used in the current study to determine the degree of depression among the respondents. Participants were provided with a series of statements to evaluate the symptoms of depression in them. (e.g., "I do not feel like going out anymore and talking to anyone" or "I have nothing left to look forward to"). Participants were instructed to rate the statements on a 4-point Likert scale indicating their emotions in the past 1 month. $(1=$ never felt so, 2 = occasionally, $3=$ most of the time, $4=$ every time). All the items from the analysis were summed up to find out the total score ranging from 0-21. However, higher scores represented greater symptoms of depression. The reliability and validity of the analysis were checked and it was found that Cronbach's alpha value was 0.94.

The Short Health Anxiety Inventory (SHAI) [14, 15] method is used to find out how far the respondents have developed anxiety issues related to their health. However, it is an 18-item self-analysis method used to measure the health anxiety symptoms. For every question asked, every participant is required to choose one option out of 4 options provided. (e.g., 1 = "I never worried about my health in this crisis", 2 = "I rarely worried about my health in this crisis", 3 = "I was literally worried about my health in this crisis", 4 = "I was mostly worried about my health in this crisis"). After receiving all the responses, the value of items was summed up and it ranged between 18 and 72 . However, respondents with high scores were pointed with high health anxiety. However, the SHAI measure used exhibited a good reliability of 0.96 as Cronbach's alpha value.

Financial Stress was measured by using Family Economic Strain Scale (FESS) [16] which measures the degree of stress imbued from financial crisis in upcoming future (e.g., I was stressed that I will not have any money left in my hand in the near future). Participants were forwarded with few statements and they were asked to rate them using 5-point Likert-type scale that ranges from 1 to 5 . ( $1=$ never, $2=$ rarely, $3=$ few times, $4=$ many times, $5=$ always). The summed up scores ranges from 3 to 15 and respondents with higher scores were marked as more financially stressful. The reliability and validity of the analysis were checked and it was found that Cronbach's alpha value was 0.96 .

The UCLA Loneliness scale-Version 3 (ULS-3) [17] measures the extent to which the respondents feel lonely in the COVID-19 Pandemic scenario. It is a self-measuring analysis of 20 items report. (e.g., "I have no companionship" or "I feel left out"). Participants were forwarded with 20 statements and they were asked to rate them using 5-point Likert-type scale that ranges from 1(never) to 4(often). The summed up scores ranges from 20 to 80 and respondents with higher scores were marked as more financially stressful. The reliability and validity of the analysis were checked and it was found that Cronbach's alpha value was 0.94 .

Multidimensional Scale of Perceived Social Support (MSPSS) [18] is a 12-item scale used to measure the availability of social support to any individual from predetermined primary sources such as friends (e.g., "I can discuss my issues with my friends"), family (e.g., "I can talk to them regarding my problems without being prejudged") and significant others (e.g., "I can rely on the special person in my life"). Participants were forwarded 
with few statements and they were asked to rate them using 7-point Likert-type scale that ranges from 1(very strongly agree) to 7 (very strongly disagree). The summed up scores ranges from 12 to 84 and respondents with higher scores were marked as more financially stressful. The reliability and validity of the analysis was checked and it was found that Cronbach's alpha value was 0.96 .

\section{Discussion}

\section{Association of Social distancing and Lockdown constraints with Psychological Outcomes}

The transgender individuals who reflected the symptoms of coronavirus infection were subjected to violence, verbal assaults and bullying in quarantine centers turning quarantine experiences as their worst nightmare. A transgender named Meena from Ganjam district, Odisha faced a number of problems when she was quarantined with 14 men where she was subjected to cruel taunts, verbal assaults and crass questions over her sexuality. Even after complaining several times to the local administration, still she could not avail any separate ward. She said "It was the worst nightmare so far in my life. However, most of the times, I preferred to sit in the playground and avoided staying inside quarantine room such that I would be at ease." Further sharing her experience, a 28-year transgender from Mumbai said that "Use of lady's toilets in quarantine center was a traumatic experience for me. A lady screamed at me and ran away out of disgust after finding me in the washroom. I felt so bad that I reduced the consumption of water so that I need not visit washroom more often. But this was not just enough. A laboratory assistant who collected blood samples from me asked me how much do I charge for a night? Even after complaining against him, nobody took any action against him. This made me quit the quarantine center and I would prefer home quarantine rather than getting admitted to any quarantine center." Similarly, another transgender from Hyderabad naming
Shylaja was quarantined in a government hospital with 3 other men where was verbally abused and criticized which made her days difficult in the ward. Thus, the transgender corona active patients go through sarcastic comments and dirty looks in quarantine houses which is a matter of concern. Taking into account these inconveniences faced by transgender patients in COVID-19 quarantine centers, Manipur government has set up 2 separate quarantine centers for LGBTQ patients with a capacity of 40 patients each [19].

Further, staying in hostile homes, social distancing from loved ones, financial stress, lockdown constraints, delay in provision of essential hormonal therapies, cancellation of appointment with psychiatrists, postponement of planned sex reassignment surgeries have brought in depressive symptoms in transgender individuals. A transgender naming Dan Rebello from Thane is open to verbal abuses, criticism and taunts in her home amid lockdown by her parents. However, she is afraid that they will force her to marry in this lockdown and if not then these verbal assaults will soon turn into physical abuses. She was previously suffering from anxiety issues and this situation may trigger it. Thus, she decided to stay inside her room to keep distance from her parents. Similarly, a makeup artist transgender naming Pam from New Delhi is under depression and constantly facing anxiety issues amid this lockdown due her clogged income. She was planning for sex reassignment surgery which she considers as impossible now due to her exhausted savings. She is experiencing panic attacks which are risky to her life. However, it is sad but true that only emergency surgery and other necessary process is being operated amid COVID-19 and all other surgeries and treatments are postponed. Sex reassignment surgery is considered as essential but not an emergency surgery. As a result of which an HIV transgender patient naming Shonali from Kolkata is facing health anxiety as her next check-up is postponed for indefinite time. The postponement of appointments with psychiatrists put psychic transgender patients at risk of mental imbalance. A freelancer writer Sasha living at Bangalore is at the verge

Table 1 Degree of Association among psychological outcomes, social distancing and lockdown

\begin{tabular}{|c|c|c|c|c|c|c|c|}
\hline Variables & 1 & 2 & 3 & 4 & 5 & 6 & 7 \\
\hline 1. Social distancing & - & 0.717 & 0.805 & 0.778 & 0.676 & 0.801 & 0.805 \\
\hline 2. Lockdown constraint & & - & 0.891 & 0.867 & 0.775 & 0.912 & 0.534 \\
\hline 3. Depression symptoms & & & - & 0.953 & 0.768 & 0.931 & 0.898 \\
\hline 4. Anxiety related to health & & & & - & 0.805 & 0.909 & 0.901 \\
\hline 5. Financial stress & & & & & - & 0.802 & 0.771 \\
\hline 6. Loneliness & & & & & & - & 0.945 \\
\hline 7. Lack of social support & & & & & & & - \\
\hline Mean & & 3.18 & 14.66 & 46.15 & 11.20 & 54.24 & 39.83 \\
\hline
\end{tabular}


of transition into female since September 2019 through several hormonal therapies. Unfortunately, amid this lockdown, she is unable to meet her doctor for her regular checkup. She is unable to discover the changes in her body and is afraid of being overdosed. However, she is prone to depression and anxiety issues and unable to meet her psychiatrist who stays $20 \mathrm{~km}$ away. This is life threatening scenario for her. Thus, the looming fear among transgender people about the uncertain situation amid COVID-19 Pandemic further pushes them toward depression and other mental health imbalance issues (Priyadarshini et al. 2020a).

Psychological outcomes including depression, health anxiety, financial stress, loneliness, lack of social support are ascertained along with social distancing and lockdown constraint. Degree of association between any two of these variables are computed and presented in Table 1.

As exhibited in Table 1, it is evident that there is positive association between any two of the variables and the degree of association is quite reasonable with the range from 0.534 to 0.945 . The degree of association is the highest between 'lack of social support' and 'loneliness'. On the other hand, the association level is the least between 'lockdown constraint' and 'lack of social support'.

\section{Analysis of Psychological Outcomes:}

\section{Depression}

The criterion variable is 'Depression is prevalent among transgender community amid COVID-19 pandemic', i.e., V5, for which four independent variables such as 'Social distancing' (V1), 'Lockdown constraint' (V2), 'Income per month' (V3), 'Education Attainment' (V4) are taken into consideration. The Null Hypothesis is-Depression is not prevalent among transgender community amid COVID-19 pandemic. From the noticeable depression symptoms, the Depression Anxiety Stress Scales (DASS-21) are considered as significant $(p<0.05)$ with $2.3 \%$ of the variance. As the significance level calculated is less than the presumed level of significance of 5\%, the Null Hypothesis is not accepted. Thus, Depression is prevalent among transgender community amid COVID-19 pandemic. Since for the variables V1, V2, V3, and V4, the calculated significance level is less than the accepted level of significance of $5 \%$ (i.e., 0.05), as presented in Table 2, these four variables highly influence the criterion variable to a significant extent $[F(4,145)=2.17$ and $\Delta \mathrm{R} 2=0.00]$ rejecting the null hypothesis.

The output furnishes the following regression model $\mathrm{V} 5=.580+3.725 \mathrm{~V} 1+2.305 \mathrm{~V} 2-0.291 \mathrm{~V} 3-0.440 \mathrm{~V} 4$

The Standardized coefficients ( $\beta$ value) for the model follows V4 $>\mathrm{V} 1>\mathrm{V} 2>\mathrm{V} 3$. The income per month (V3) and education attainment (V4) are uniquely significant but negatively associated with depression symptoms, whereas Social distancing impact (V1), Lockdown constraint (V2) are uniquely significant but positively associated with depression symptoms.

\section{Anxiety Issues related to Health}

The criterion variable is "Anxiety related to health is prevalent among transgender community amid COVID-19 pandemic", i.e., V5, for which four independent variables such as Social distancing (V1), Lockdown constraint (V2), Income per month (V3), Education Attainment (V4) are taken into consideration. The Null Hypothesis is-Anxiety related to health is not prevalent among transgender community amid COVID-19 pandemic. From the noticeable anxiety issues symptoms, the Short Health Anxiety Inventory (SHAI) is considered as significant $(p<0.05)$ with $6 \%$ of the variance. As the significance level calculated is less than the presumed level of significance of $5 \%$, the Null Hypothesis is not accepted. Since for the variables $\mathrm{V} 1, \mathrm{~V} 2, \mathrm{~V} 3$, and V4, the calculated significance level is less than the accepted level of significance of $5 \%$ (i.e., 0.05 ), as presented in Table 3, these four variables highly influence the criterion variable to a significant extent [F (4, $145)=1.53$ and $\Delta \mathrm{R} 2=0.00]$ rejecting the null hypothesis.

The output furnishes the following regression model

$$
\begin{aligned}
\mathrm{V} 5= & 16.075+15.36 \mathrm{~V} 1 \\
& +10.32 \mathrm{~V} 2-0.605 \mathrm{~V} 3-2.074 \mathrm{~V} 4
\end{aligned}
$$

The Standardized coefficients ( $\beta$ value) for the model follows V1 $>$ V3 $>$ V4 $>$ V2. The income per month (V3) and education attainment (V4) are uniquely significant but negatively associated with depression symptoms, whereas Social distancing impact (V1), Lockdown constraint (V2) are uniquely significant but positively associated with depression symptoms.

Table 2 Regression Output for ascertaining the influence of Predictor variable on Criterion variable (Depression)

\begin{tabular}{lllll}
\hline Model & \multicolumn{2}{l}{ Unstandardized Coefficients } & $\begin{array}{l}\text { Level of } \\
\text { Significance }\end{array}$ \\
\cline { 3 - 4 } & $\begin{array}{l}\text { Unstandardized } \\
\text { beta (B) }\end{array}$ & $\begin{array}{l}\text { Standard } \\
\text { Error }\end{array}$ & \\
\hline 1 & (Constant) & .580 & .651 & .375 \\
& V1 & 3.725 & .526 & .006 \\
V2 & 2.305 & .159 & .008 \\
V3 & -.291 & .257 & .040 \\
V4 & -.440 & .172 & .001 \\
\hline
\end{tabular}


Table 3 Regression Output for ascertaining the influence of Predictor variable on Criterion variable (Anxiety on health)

\begin{tabular}{|c|c|c|c|c|}
\hline \multirow{2}{*}{\multicolumn{2}{|c|}{ Model }} & \multicolumn{2}{|c|}{ Unstandardized Coefficients } & \multirow{2}{*}{$\begin{array}{l}\text { Level of } \\
\text { Significance }\end{array}$} \\
\hline & & $\begin{array}{l}\text { Unstandardized } \\
\text { beta (B) }\end{array}$ & $\begin{array}{l}\text { Standard } \\
\text { Error }\end{array}$ & \\
\hline \multirow[t]{5}{*}{2} & (Constant) & 16.075 & 3.434 & .000 \\
\hline & V1 & 15.365 & 2.774 & .002 \\
\hline & V2 & 10.326 & .839 & .043 \\
\hline & V3 & -.605 & 1.355 & .005 \\
\hline & V4 & -2.074 & 907 & .024 \\
\hline
\end{tabular}

\section{Loneliness}

The criterion variable is "Loneliness is predominant among transgender community amid COVID-19 pandemic", i.e., V5, for which four independent variables such as Quarantine impact (V1), COVID Impact (V2), Income per month (V3), Education Attainment (V4) are taken into consideration. The Null Hypothesis is-Loneliness is not predominant among transgender community amid COVID19 pandemic. From the noticeable anxiety issues symptoms, the UCLA Loneliness scale-Version 3 (ULS-3) is considered as significant $(p<0.05)$ with $9 \%$ of the variance. As the significance level calculated is less than the presumed level of significance of 5\%, the Null Hypothesis is not accepted. Since for the variables V1 and V2, the calculated significance level is less than the accepted level of significance of $5 \%$ (i.e., 0.05), as presented in Table 4 , rejecting the null hypothesis, these two variables do influence the criterion variable to a significant extent where as for V3 and V4, the calculated significance level is more than the accepted level of significance of $5 \%$ [F (4, $145)=2.64$ and $\Delta \mathrm{R} 2=0.00]$.

The output furnishes the following regression model

Table 4 Regression Output for ascertaining the influence of Predictor variable on Criterion variable (Loneliness)

\begin{tabular}{|c|c|c|c|c|}
\hline \multirow{2}{*}{\multicolumn{2}{|c|}{ Model }} & \multicolumn{2}{|c|}{ Unstandardized Coefficients } & \multirow{2}{*}{$\begin{array}{l}\text { Level of } \\
\text { Significance }\end{array}$} \\
\hline & & $\begin{array}{l}\text { Unstandardized } \\
\text { beta (B) }\end{array}$ & $\begin{array}{l}\text { Standard } \\
\text { Error }\end{array}$ & \\
\hline \multirow[t]{5}{*}{3} & (Constant) & 7.629 & 2.742 & .006 \\
\hline & V1 & 16.012 & 2.215 & .048 \\
\hline & $\mathrm{V} 2$ & 11.321 & 670 & .008 \\
\hline & V3 & 1.837 & 1.082 & .092 \\
\hline & V4 & .812 & .724 & .264 \\
\hline
\end{tabular}

Table 5 Regression Output for ascertaining the influence of Predictor variable on Criterion variable (Lack of Social support)

\begin{tabular}{|c|c|c|c|c|}
\hline \multirow{2}{*}{\multicolumn{2}{|c|}{ Model }} & \multicolumn{2}{|c|}{ Unstandardized Coefficients } & \multirow{2}{*}{$\begin{array}{l}\text { Level of } \\
\text { Significance }\end{array}$} \\
\hline & & $\begin{array}{l}\text { Unstandardized } \\
\text { beta (B) }\end{array}$ & $\begin{array}{l}\text { Standard } \\
\text { Error }\end{array}$ & \\
\hline \multirow[t]{5}{*}{4} & (Constant) & 18.832 & 4.565 & .000 \\
\hline & V1 & 25.815 & 3.688 & .006 \\
\hline & $\mathrm{V} 2$ & 10.714 & 1.115 & .028 \\
\hline & V3 & -.543 & 1.802 & .003 \\
\hline & V4 & -.884 & 1.206 & .002 \\
\hline
\end{tabular}

$\mathrm{V} 5=7.629+16.012 \mathrm{~V} 1+11.32 \mathrm{~V} 2$

The Standardized coefficients ( $\beta$ value) for the model follow V2 > V1. The Quarantine impact (V1) and COVID Impact (V2) strongly contribute to loneliness of the queers. However, income and education are not significant in influencing loneliness.

\section{Lack of Social Support}

The criterion variable is "Lack of Social Support is predominant among transgender community amid COVID-19 pandemic", i.e., V5, for which four independent variables such as Social distancing impact (V1), Lockdown constraint (V2), Income per month (V3), Education Attainment (V4) are taken into consideration. The Null Hypothesis is-Lack of Social Support is not predominant among transgender community amid COVID-19 pandemic. From the noticeable lack of social support symptoms, Multidimensional Scale of Perceived Social Support (MSPSS) is considered as significant $(p<0.05)$ with $14 \%$ of the variance. As the significance level calculated is less than the presumed level of significance of $5 \%$, the Null Hypothesis is not accepted. Since for the variables V1, V2, $\mathrm{V} 3$, and V4, the calculated significance level is less than the accepted level of significance of $5 \%$ (i.e., 0.05), as presented in Table 5, these four variables influence the criterion variable to a significant extent $[\mathrm{F}(4,145)=1.32$ and $\Delta \mathrm{R} 2=0.00]$ rejecting the null hypothesis.

The output furnishes the following regression model

$$
\begin{aligned}
\mathrm{V} 5= & 18.832+25.815 \mathrm{~V} 1+10.714 \mathrm{~V} 2-0.543 \mathrm{~V} 3 \\
& -0.884 \mathrm{~V} 4
\end{aligned}
$$

The Standardized coefficients ( $\beta$ value) for the model follows V4 $>$ V3 $>$ V1 $>$ V2. The income per month (V3) and education attainment (V4) are uniquely significant but negatively associated with lack of social support symptoms, whereas Social distancing impact (V1), COVID Impact (V2) are uniquely significant but positively associated with depression symptoms. 
Table 6 Regression Output for ascertaining the influence of Predictor variable on Criterion variable (Financial stress)

\begin{tabular}{|c|c|c|c|c|}
\hline \multirow{2}{*}{\multicolumn{2}{|c|}{ Model }} & \multicolumn{2}{|c|}{ Unstandardized Coefficients } & \multirow{2}{*}{$\begin{array}{l}\text { Level of } \\
\text { Significance }\end{array}$} \\
\hline & & $\begin{array}{l}\text { Unstandardized } \\
\text { beta (B) }\end{array}$ & $\begin{array}{l}\text { Standard } \\
\text { Error }\end{array}$ & \\
\hline \multirow[t]{5}{*}{5} & (Constant) & 3.079 & .710 & .000 \\
\hline & V1 & 1.922 & .573 & .031 \\
\hline & $\mathrm{V} 2$ & 1.466 & .173 & .068 \\
\hline & V3 & -.263 & .280 & .009 \\
\hline & V4 & -.311 & .187 & .019 \\
\hline
\end{tabular}

\section{Financial Stress}

The criterion variable is "Financial stress is predominant among transgender community amid COVID-19 pandemic", i.e., V5, for which four independent variables such as Social distancing impact (V1), Lockdown constraint (V2), Income per month (V3), Education Attainment (V4) are taken into consideration. The Null Hypothesis is-Financial stress is not predominant among transgender community amid COVID-19 pandemic. From the noticeable lack of social support symptoms, Financial Stress was measured by using Family Economic Strain Scale (FESS) is considered as significant $(p<0.05)$ with $18 \%$ of the variance. As the significance level calculated is less than the presumed level of significance of $5 \%$, the Null Hypothesis is not accepted. Since for the variables V1, V3 and V4, the calculated significance level is less than the accepted level of significance of $5 \%$ (i.e., 0.05), as presented in Table 6 , these three variables significantly influence the criterion variable. However, for V2, the calculated significance level is more than the accepted level of significance of 5\% (i.e., 0.05) and hence this variable does not have significant influence on criterion variable, $[\mathrm{F}$ (4, $145)=2.64$ and $\Delta \mathrm{R} 2=0.00]$.

The output furnishes the following regression model

$\mathrm{V} 5=3.079+1.922 \mathrm{~V} 1-0.263 \mathrm{~V} 3-0.311 \mathrm{~V} 4$

The Standardized coefficients ( $\beta$ value) for the model follow V3 $>$ V4 $>$ V1. The income per month (V3) and education attainment (V4) are uniquely significant but negatively associated with financial stress symptoms, whereas Quarantine impact (V1) is uniquely significant but positively associated with financial stress symptoms.

\section{Results}

\section{Degree of Association among psychological outcomes, social distancing and lockdown}

As presented in Section-3 of this Paper, there has been strong association among social distancing, lockdown constraints and psychological outcomes like depression, health anxiety, financial stress, loneliness, lack of social support. As ascertained through the degree of association between any of these two variables, it is found that there is almost high degree of positive association between any two of these variables. Lack of social support and loneliness has the highest level of association with the correlation coefficient value of 0.945 . Thus, lack of social support owing to COVID-19 gets resulted in loneliness among the queers and also loneliness among the queers due to COVID-19 make them deprived of social support. However, lockdown constraint and lack of social support have the lowest level of association with the correlation coefficient value of 0.534. Although lockdown constraint restricts social support, it fails to completely wipe out the social support. In spite of lockdown constraints, people are helping each other, of course with caution and limitation. That's why the degree of association is just above $50 \%$ and the lowest among any other two variables.

\section{Is Depression prevalent among transgender community amid COVID-19 pandemic?}

Null Hypothesis: Depression is not prevalent among transgender community amid COVID-19 pandemic.

On the basis of Regression output, the Null Hypothesis is not accepted and hence it is inferred that Depression is prevalent among transgender community amid COVID-19 pandemic. Two variables; 'Social distancing impact' and 'Lockdown constraint' are uniquely significant but positively associated with depression symptoms. Thus, higher the quarantine impact, higher is the depression symptoms among queers and the vice versa. Similarly, stricter the lockdown constraint, higher is the depression symptoms and the vice versa. On the other hand, two variables; income per month and education attainment are uniquely significant but negatively associated with depression symptoms. Thus, higher the income per month, lesser is the depression symptoms among the queers and the vice versa. Similarly, higher the education attainment, lesser is the depression symptoms and the vice versa. 
Is Anxiety related to health prevalent among transgender community amid COVID-19 pandemic?

Null Hypothesis: Anxiety related to health is not prevalent among transgender community amid COVID-19 pandemic.

On the basis of Regression output, the Null Hypothesis is not accepted and hence it is inferred that anxiety related to health is prevalent among transgender community amid COVID-19 pandemic. Two variables; 'Social distancing impact' and 'Lockdown constraint' are uniquely significant but positively associated with anxiety related to health. Thus, higher the quarantine impact, more is the anxiety related to health among queers and the vice versa. Similarly, stricter the lockdown constraint, higher is the anxiety related to health and the vice versa. On the other hand, two variables; income per month and education attainment are uniquely significant but negatively associated with anxiety related to health. Thus, higher the income per month, lesser is the anxiety related to health among the queers and the vice versa. Similarly, higher the education attainment, lesser is the anxiety related to health and the vice versa.

\section{Is Loneliness predominant among transgender community amid COVID-19 pandemic?}

Null Hypothesis: Loneliness is not predominant among transgender community amid COVID-19 pandemic.

On the basis of Regression output, the Null Hypothesis is not accepted and hence it is inferred that loneliness is predominant among transgender community amid COVID19 pandemic. Two variables, out of four; Social distancing impact and Lockdown Constraint Impact strongly contribute to loneliness of the queers. Stricter the quarantine impact, higher is the level of loneliness and the vice versa. Similarly, intense the COVID Impact, higher is the level of loneliness among the queers. However, income and education are not significant in influencing loneliness.

\section{Is Lack of Social Support predominant among transgender community amid COVID-19 pandemic?}

Null Hypothesis: Lack of Social Support is not predominant among transgender community amid COVID-19 pandemic.

On the basis of Regression output, the Null Hypothesis is not accepted and hence it is inferred that lack of social support is predominant among transgender community amid COVID-19 pandemic. Two variables; 'Social distancing impact' and 'Lockdown Constraint Impact' are uniquely significant but positively associated with lack of social support. Thus, higher the quarantine impact, more is the lack of social support among queers and the vice versa. Similarly, stricter the lockdown constraint, intense is the lack of social support and the vice versa. On the other hand, two variables; income per month and education attainment are uniquely significant but negatively associated with lack of social support. Thus, higher the income per month, lesser is the lack of social support among the queers and the vice versa. It means, richer transgender experience lesser extent of lack of social support even during COVID-19 pandemic. Similarly, higher the education attainment, lesser is the lack of social support and the vice versa.

\section{Is Financial stress predominant among transgender community amid COVID-19 pandemic?}

Null Hypothesis: Financial stress is not predominant among transgender community amid COVID-19 pandemic.

On the basis of Regression output, the Null Hypothesis is not accepted and hence it is inferred that financial stress is predominant among transgender community amid COVID-19 pandemic. Two variables; income per month and education attainment are uniquely significant but negatively associated with financial stress symptoms, whereas Social distancing impact is uniquely significant but positively associated with financial stress symptoms. Thus, higher the income per month, lesser is the financial stress symptoms among queers and the vice versa. Similarly, higher the education attainment, lesser is the financial stress symptoms among queers and the vice versa. On the contrary, stricter the lockdown impact, more is the financial stress symptoms among queers and the vice versa.

\section{Conclusion}

The crisis amid COVID-19 pandemic has brought in international health trepidation as well as psychological suffering in the globe. Unfortunately, the transgender section being the secluded community of the society, is subjected to greater difficulties amid this pandemic. The majority of the transgender community is indulged in informal sources of income mostly by begging, selling sex, street entertaining and other menial jobs which requires social interactions. However, to curtail the spread of corona virus infection, nationwide shutdown or lockdown is declared halting the income of the transgender individuals for an uncertain period. Consequently, the lost livelihood, clogged income stream, exhausted savings, burden of debt has imbued psychological distress among them. The research work discovered that most of the transgender respondents exhibited the symptoms of depression, anxiety issues, financial stress instilled in them due to lack of social support and loneliness with respect to their income, 
education and nature of job. Along with the financial dearth, delay in provision of essential hormonal therapies, cancellation of appointment with psychiatrists, stuck in hostile homes and postponement of sex reassignment surgeries psychologically disturbs them me in this tough times. Social distancing, nationwide lockdown or shutdown, staying in quarantines is provoking the transgender people to commit suicide by surrounding them with pessimistic thoughts. This has pushed this ostracized community toward the dead end.

Further the limited assistance from the government toward the transgender community is a matter of chief concern in their survival. Lack of necessary documentations with transgender people such as Aadhaar card, ration card, bank account and Voter-Id card prohibit them from accessing financial aid and welfare schemes from the state. This has pushed transgender people at heightened risk of hunger, poverty and clogged income stream which has worsened their socioeconomic status and has imbalanced their mental state. Slowly but surely, this will be a silent killer ruining the lives of transgender people amid this pandemic situation. Further, there is a necessity for policy formulation in favor of this marginalized community to endow them with basic essentials amid this crisis irrespective of their identity related documents. However, keeping an eye on the unpredictable future, transgender population should be provided with essential facilities to be educated enough such that they can be eligible enough to access a suitable job so that they can operate from online podium rather than depending on the gig jobs for their daily bread and butter.

\section{References}

1. World Health Organization. (2020). Rolling updates on coronavirus disease (COVID-19). https://www.who.int/emergencies/ diseases/novel-coronavirus-2019/events-asthey-happen.

2. S. Flaxman, S. Mishra, A. Gandy, H. J. T. Unwin, H. Coupland, T. A. Mellan, H. Zhu, T. Berah, J. W. Eaton, P. N. P. Guzman, N. Schmit, L. Callizo, I. C. C.-19 R. Team, C. Whittaker, P. Winskill, X. Xi, A. Ghani, C. A. Donnelly, S. Riley, ... S. Bhatt, Estimating the number of infections and the impact of nonpharmaceutical interventions on COVID-19 in European countries: Technical description update. (2020). arXiv: 2004.11342 [q-Bio, Stat]. http://arxiv.org/abs/2004.11342

3. G.J. Asmundson, S. Taylor, How health anxiety influences responses to viral outbreaks like COVID-19: What all decisionmakers, health authorities, and health care professionals need to know. J. Anxiety Disord. 71, 102211 (2020)

4. P. Courtet, E. Olié, C. Debien, G. Vaiva, Keep socially (but not physically) connected and carry on: Preventing suicide in the age of COVID-19. J. Clin. Psychiatry. 81 20com13370 (2020)
5. M.A. Reger, I.H. Stanley, T.E. Joiner, Suicide mortality and coronavirus disease 2019-A perfect storm? JAMA Psychiatry. (2020) https://doi.org/10.1001/jamapsychiatry.2020.1060.

6. Perez-Brumer, A., Silva-Santisteban A. (2020). COVID-19 policies can perpetuate violenceagainst transgender communities: insights from Peru. AIDS Behav 2020; published onlineApril 27. https://doi.org/10.1007/s10461-020-02889-z.

7. Trivedi, D. (2020). COVID-19 and the plight of the transgender community. https://frontline.thehindu.com/dispatches/article314 63945.ece

8. S. Priyadarshini, S.C. Swain, Impact of COVID-19 on the Socioeconomic life and Psychology of Transgenders: Insights from India. Int. J. Res. Pharmaceutical Sci. 11(SPL1), 126-132 (2020). https://doi.org/10.26452/ijrps.v11iSPL1.2286

9. S. Priyadarshini, S.C. Swain, Life of Transgender in Ethical Milieu: A Study of Selected Transgenders of Bhubaneswar India. Acad. J. Interdiscip. Stud. 9(4), 125 (2020). https://doi.org/10.36941/ajis-2020-0067

10. X. Zhu, Y. Gao, A. Gillespie, X. Ying, Q. Ji, O. Jianjun, Z. Shaoling, K. Peng, T. Tingting, W. Chaoyue, C. Runsen, Health care and mental health challenges for transgender individuals during the COVID-19 pandemic. Lancet Diabetes Endocrinol. 8(7), 564-565 (2020). https://doi.org/10.1016/S2213-8587 (20)30182-0

11. L. Hawryluck, W.L. Gold, S. Robinson, S. Pogorski, S. Galea, R. Styra, SARS control and psychological effects of quarantine, Toronto. Canada. Emerg. Infect. Dis. 10, 1206-1212 (2004)

12. M.G. Wheaton, J.S. Abramowitz, N.C. Berman, L.E. Fabricant, B.O. Olatunji, Psychological predictors of anxiety in response to the H1N1 (swine flu) pandemic. Cognit. Ther. Res. 36, 210-218 (2012)

13. P.F. Lovibond, S.H. Lovibond, The structure of negative emotional states: comparison of the depression anxiety stress scales (DASS) with the beck depression and anxiety inventories. Behav. Res. Ther. 33, 335-343 (1995)

14. J.S. Abramowitz, B.J. Deacon, D.P. Valentiner, The Short Health Anxiety Inventory: Psychometric properties and construct validity in a non-clinical sample. Cognit. Ther. Res. 31, 871-883 (2007)

15. P.M. Salkovskis, K.A. Rimes, H.M.C. Warwick, D.M. Clark, The Health Anxiety Inventory: Development and validation of scales for the measurement of health anxiety and hypochondriasis. Psychol. Med. 32, 843-853 (2002)

16. J.M. Hilton, E.L. Devall, The Family Economic Strain Scale: Development and evaluation of the instrument with single-and two-parent families. J. Fam. Econ. Issues. 18, 247-271 (1997)

17. D.W. Russell, UCLA loneliness scale (Version 3): Reliability, validity, and factor structure. J. Pers. Assess. 66, 20-40 (1996)

18. G.D. Zimet, N.W. Dahlem, S.G. Zimet, G.K. Farley, The multidimensional scale of perceived social support. J. Pers. Assess. 52, 30-41 (1988)

19. R. Chitra, Queer in quarantine: Verbal assaults, bullying \&amp; crass jokes make quarantine experience a nightmare for transgenders | India News-Times of India. https://timesofindia. indiatimes.com/india/queer-in-quarantine-verbal-assaults-bullyingcrass-jokes-make-quarantine-experience-a-nightmare-for-trans genders/articleshow/76114890.cms (2020)

Publisher's Note Springer Nature remains neutral with regard to jurisdictional claims in published maps and institutional affiliations. 